exposed in controlled conditions (silent room, active sleep, randomised order) to three odours presented on a Q-tips:

- water (control);

- a hand rub $\left(\mathrm{DES} 60^{\circledR}\right)$ diluted to match the odour's intensity released by hands;

- an adhesive remover (Convacare ${ }^{\circledR}$ ).

We recorded bilaterally cortical activation in orbito-frontal gyri (OFG), prefrontal (PFC) and somatosensory (S1 and S2) cortices during 40s (10s-baseline, 10s-presentation, 20s-poststimuli) by multichannel-NIRS. $\mathrm{HbO} 2$ changes were analysed from baseline (ANOVA) and by subgroups (Kruskall-Wallis).

Results In the whole population, we observed:

- no activations for water.

- cortical activations $\left(\mathrm{HbO}_{2}\right.$ increase) for $\mathrm{DES60}^{\circledR}(\mathrm{p}<$ 0.001 ), unilaterally in OFG, PFC, and bilaterally in S1 and S2; whereas only in S1 (unilaterally) for Convacare ${ }^{\circledR}(p<0.001)$.

We noticed significant profiles of response for all infant's subgroups, in at least one olfactory and one pain processing areas. The average magnitude of $\mathrm{HbO}_{2}$ increase from baseline was higher in full-terms vs both subgroups of preterms: $8.5(2.8-$ 12.6) $\mu \mathrm{mol} / \mathrm{l}$ vs $5.9(2.6-10.4)$ and $5.7(1.8-9.2) \mu \mathrm{mol} / \mathrm{l}$ for DES60 ${ }^{\circledR}(\mathrm{p}<0.001)$.
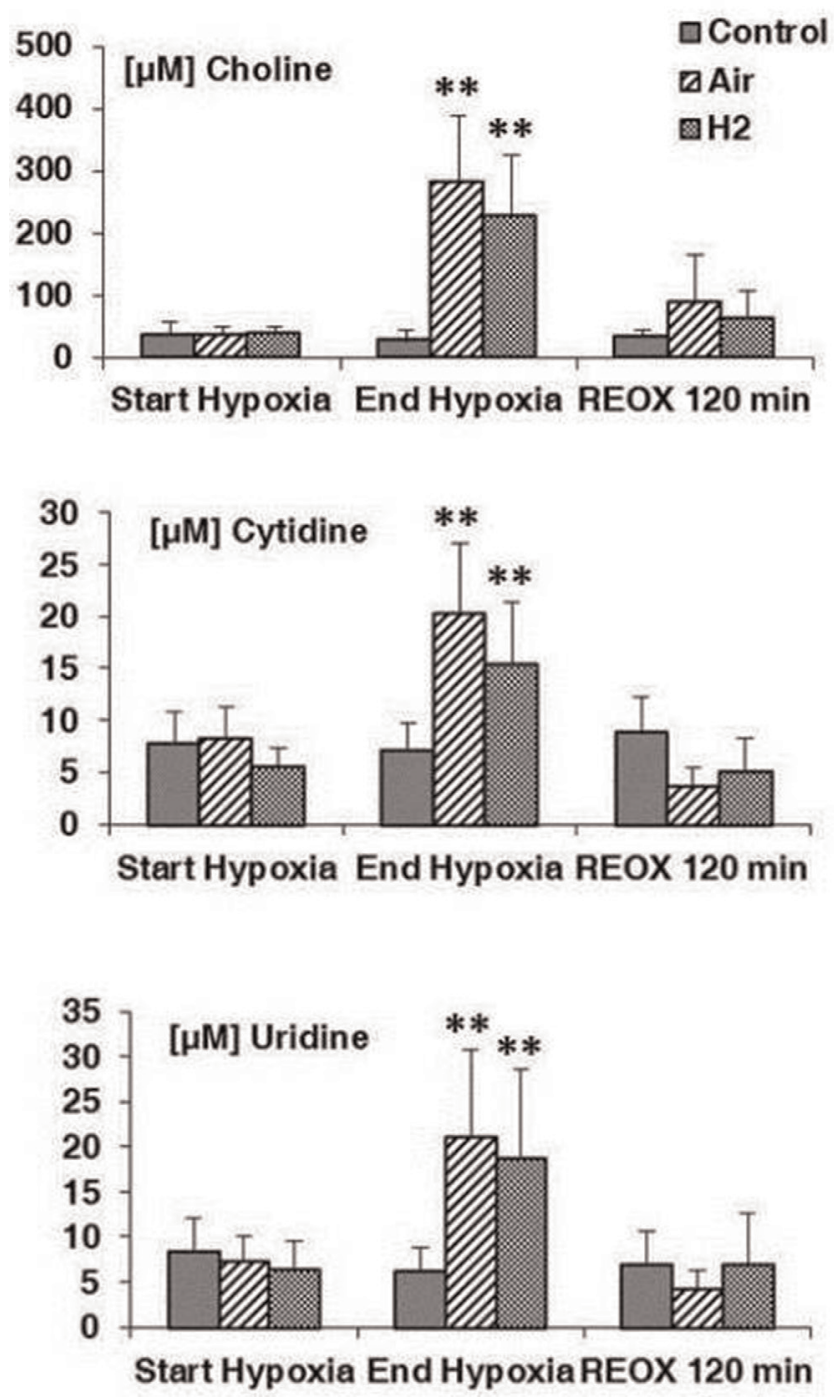

Abstract P0-0414 Figure 1 Choline, cytidine and uridine levels before and after hypoxia as well as after resuscitation
Conclusion Full-term and preterm newborns can perceive OS at a cortical level. Exposure to OS can activate trigeminal/olfactory and pain processing areas and may induce discomfort/pain in newborns.

\section{P0-0414 PLASMA METABOLOME IN A NEWBORN PIGLET MODEL FOR ASPHYXIA AND RESUSCITATION}

1J Kuligowski, ${ }^{2} \mathrm{R}$ Solberg, ${ }^{1} \mathrm{~J}$ Escobar, ${ }^{3} \mathrm{G}$ Quintás, ${ }^{1} \mathrm{I}$ Lliso, ${ }^{2} \mathrm{OD}$ Saugstad, ${ }^{4} \mathrm{M}$ Vento. ${ }^{1}$ Neonatal Research Group, Health Research Institute Hospital La Fe, Valencia, Spain; ${ }^{2}$ Department of Pediatric Research, Oslo University Hospital - Rikshospitalet, Oslo, Norway; ${ }^{3}$ Leitat Technological Center, Bio In Vitro Division, Valencia, Spain; ${ }^{4}$ Division of Neonatology, University and Polytechnic Hospital La Fe, Valencia, Spain

\subsection{6/archdischild-2014-307384.1059}

Background and aims Post-asphyxia resuscitation with air improves survival. We aimed to find reliable biomarkers of brain injury secondary to hypoxia/ischemia in plasma in a newborn piglet model for asphyxia.

Methods Hypoxia was introduced to newborn piglets (standardised model). Plasma metabolomic profiles reflecting the effects of asphyxia and resuscitation were studied, and changes in target metabolites of the Kennedy pathway were analysed by LC-MS.

Results A set of metabolites reflecting metabolic changes after asphyxia and resuscitation was identified. Increased levels of choline, cytidine and uridine (Kennedy pathway) during hypoxia were observed (see Figure 1). No differences were found between resuscitation using air and air $+2.1 \% \mathrm{H}_{2}$.

Conclusions Untargeted metabolomics enabled the monitorization of changes occurring during asphyxia and resuscitation on a molecular level. A set of candidate biomarkers was identified. In accordance to previous results, alterations in the Kennedy pathway are reported. The performance of candidate biomarkers for clinical grading will be evaluated in further studies.

Acknowledgments JK and JE acknowledge Sara Borrell grants CD11/00154 and CD12/00667. MV acknowledges the FISPI1/ 0313 and EC11-246 grant. The Laerdal Foundation (Norway) supported this study.

\section{PO-0415 CORPUS CALLOSUM SIZE AS A PREDICTOR OF VISUAL PROBLEMS AMONG 4-YEAR-OLD VERY LOW BIRTH WEIGHT CHILDREN}

${ }^{1} \mathrm{P}$ Kwinta, ${ }^{1} \mathrm{M}$ Klimek, ${ }^{2} \mathrm{~A}$ Lesniak, ${ }^{3}$ I Herman-Sucharska, ${ }^{3} \mathrm{P}$ Karcz, ${ }^{2} \mathrm{~A}$ Kubatko-Zielinska, ${ }^{1}$ W Durlak, ${ }^{2} \mathrm{~B}$ Romanowska-Dixon, ${ }^{1} \mathrm{JJ}$ Pietrzyk. ${ }^{1}$ Department of Pediatrics, Jagiellonian University, Krakow, Poland; 'Department of Ophtalmology and Occular Oncology, Jagiellonian University, Krakow, Poland; ${ }^{3}$ Department of Electroradiology, Jagiellonian University, Krakow, Poland

\subsection{6/archdischild-2014-307384.1060}

Background Correlation between corpus callosum (CC) size and motor performance in prematurely born children has been described. It is speculated that the organisation of CC can be associated with visual acuity in preterm children.

Aim To assess the relation between CC size and vision impairment, results of Frostig test of visual perception and Visual evoked potentials (VEP) in a group of VLBW children.

Methods 40 children born with a mean birthweight of $1023 \mathrm{~g}$ (SD 230g) were evaluated at the mean age of 4 years (range 3.7-4.3). The children were examined for clinical signs of vision impairment and were subjected to Frostig test. VEP was recorded after checkerboard pattern and flash stimulation. 